\title{
Reversibility and death: a reply to David J Cole
}

\author{
David Lamb Manchester University
}

\section{Author's abstract}

In this reply to David $\mathcal{f}$ Cole it is argued that the medical concept of death as an irreversible phenomenon is correct and that it does not conflict with ordinary concepts of death.

Arguments claiming superiority of brain-related criteria for death over traditional cardio-respiratory criteria have frequently appealed to the fact of irreversible loss of function. Whilst loss of heartbeat can be restored or even replaced by a transplant organ or artifact dead neurons cannot regenerate and a dead brainstem cannot be replaced or its functions restored. Several claims have been made regarding the alleged restoration of function after a diagnosis of brain death - the most notorious being the BBC Panorama programme of 1980 (1). None of these claims have been substantiated. All over the world thousands of brainstem-dead ex-patients have been maintained on ventilators and meticulously observed until asystole (2). None have ever recovered.

According to David J Cole (3) the case for or against brain-related criteria for death is unaffected by empirical observations concerning the irreversible state of a dead brain. For Cole, the very concept of 'irreversible', as it is employed in medical science, is ambiguous. He argues that there is a disparity between 'medical' conceptions of death ('irreversible loss of function of all or part of the body') and 'lay, religious, and lexicographic definitions'. The former, he claims, 'forms a significant departure from the ordinary concept of death' and has 'peculiar and perhaps unacceptable consequences'. Cole's objections to the medical concept of death are bound up with his analysis of the concept of 'irreversibility'. In medicine, he claims, the 'irreversibility condition' is paramount; while the ordinary concept of death allows for reversibility.

I will argue: first, that Cole's account of 'irreversibility' is unsatisfactory as it rests on contestible philosophical assumptions about the scope of possible states of affairs, and second, that his appeal to the 'ordinary' concept of death as a reversible condition is based on a misunderstanding of the language of death in both

\section{Key words}

Death; brainstem death; irreversibility; logical possibility. religious and lay discourse.

There are, as Cole recognises, legal, moral and institutional reasons for regarding death as irreversible. These would include criteria for the disposal of remains, termination of political rights and citizenship, cessation of contractual obligations and provisions for a spouse to inherit property and re-marry. Apart from these pragmatic considerations, the belief that death is irreversible, argues Cole, 'does not appear to be a characteristic of the ordinary concept of death'. For Cole, the finality of death is contingent; irreversibility is not a logical consequence of the concept of death. This extraordinary claim is not supported by any empirical evidence which calls into question existing guidelines for diagnosing death: it is derived from a philosophical tradition which draws a sharp distinction between contingent (empirical) facts on the one hand and logically necessary truths on the other. It is, for example, an empirical fact that Jim, now cremated and his ashes spread over his favourite football pitch, will not recover from the disease which killed him. This, however, is not logically necessary. It is possible to say, with logical propriety, that 'Jim's condition is reversible'; it is factually impossible but logically possible, as the statement does not entail a contradiction. Given the distinction between the concept of 'death' in the logical and empirical senses we can understand Cole's claim that the use of 'irreversible' in the medical sense is ambiguous. For irreversibility is not a logical property of death.

It is, however, hard to see why this amounts to an acceptable criticism of the concept of 'irreversibility' in medicine. Most doctors, when asked to sign a death certificate for a putrefying corpse, discovered several weeks post-mortem, are satisfied with empirical criteria for irreversibility and lose no sleep over the possibility of misdiagnosis, even if this is not ruled out by logic. Indeed, to treat all cases of the diagnosis of death as potential misdiagnosis - as Cole's thesis suggests - would be to rob the very notion of 'misdiagnosis' of meaning. There are cases where there is no room for doubt and the introduction of doubt - because it is logically possible - is spurious. If, for example, homicide charges are brought several weeks after a murder it would not impress a jury if the defence submitted that reversibility and even complete recovery of the victim were logically possible. 


\section{The strong construal of irreversibility}

Essential to Cole's criticism of medical irreversibility is his appeal to conditions which today are irreversible but one day might be reversible. Fifty years ago end-stage renal failure was irreversibly terminal. Today, with dialysis and transplants, it is not. Cole offers a further argument against a strong construal of 'irreversibility' when he suggests that in some unspecified time $\mathrm{T}$ this patient, now dead, might be reassembled and brought back to life. On this argument criteria for treating something as a corpse would have to be abandoned. In another example he suggests that if the world were to change dramatically death might one day become reversible. The problem with these examples is that, although they refer to logical possibilities, they are under-described. Just how significantly would the world have to change? For example, a world without death would seem to be inhabited by gods. The contrast with such a world and the present one is even greater than a contrast between the world of a third world peasant with ox and bell and that of a Western yuppie with Mercedes and car-phone; the world where death has been conquered involves changes which defy implementation.

To provide a sense for his arguments against a strong construal of 'irreversibility' Cole appeals to 'exotic, as yet undeveloped or even contemplated, techniques'. These are the stuff that dreams are made of: transport faster than light, thought transference over large distances and death reversal. They all require uncontemplated techniques. These implausible speculations are finally capped with a claim that 'given the openendedness of medical progress, it is reasonable to suppose that the ability to reverse nearly any condition will be attained at some time in the future'. What does Cole mean by 'reasonable' here? $\mathrm{He}$ means that such fantastic predictions are free from contradiction. In any other sense they are unreasonable because they are implausible and certainly not evidentially powerful enough to require any change in policy guidelines for diagnosing death. Is it reasonable to practise medicine in the expectation that some future Dr Frankenstein will re-assemble long-dead corpses and bring them back to life? Of course it is logically possible, but its very implausibility renders it unsatisfactory as a guide for policy.

Appeals to logical possibility mean that certain propositions cannot be ruled out no matter how fantastic. 'It is likely', says Cole, 'that some day function may be restored to any part or the entirety of an organism'. What makes this likely? Is research underway? Are medical scientists on the verge of a breakthrough? Does Cole have evidence of this? No. It is simply that one can utter these things without contradiction.

\section{The weak construal of irreversibility}

With this kind of speculative freedom problems can easily be generated. If no one is irreversibly dead then post-mortem organ removal is not only conceptually problematic; it is ethically undesirable as it denies a person possible future use of his or her organs. To avoid these problems Cole offers medical science a weaker version of the irreversibility condition which acknowledges that some states are irreversible now, although in the future they may be reversed. But this, argues Cole, is still unsatisfactory as it introduces problematic relativities. Whilst patient $Y$ is irreversibly dead for $\operatorname{Dr} X$ at time $T$, she is potentially alive to $\operatorname{Dr} Z$ at time $\mathrm{Tl}$, for $\mathrm{Dr} Z$ has access to computer material that will reveal how to apply near miraculous therapy within minutes, thus reversing the state of Dr X's (ex)-patient. This causes problems for $\mathrm{Dr} \mathrm{X}$, who would otherwise authorise the harvesting of organs from his dead patient. For the patient could be brought back to life by Dr Z's previously uncontemplated therapy. According to Cole, Dr $\mathrm{X}$ has an ethical obligation to continue ventilating the patient beyond death because it is logically possible for some new reversible therapy to be found. Hence Cole concludes that neither the strong nor the weak construals of 'irreversibility' are free from ambiguity. But is this argument, based on the fictions of logical possibility, significantly damaging to a well-grounded diagnosis of death? Moreover, is it supported by appeals to ordinary concepts of death? The ethical problems generated by logical possibility can be met by solutions likewise generated by logical possibility. In the $\operatorname{Dr} \mathrm{X}$ scenario it is logically possible to describe a situation when the patient's organs have been removed but one minute later $\operatorname{Dr} P$ arrives from Planet $Q$ - the location of a hitherto top-secret medical research unit - with a new set of artificial organs that can be inserted into the patient, thus eliminating the grounds for Dr X's ethical dilemma. This is logically possible, just as it is possible that the editor of the $\mathcal{J} M E$ will pay me $£ 1$ million for writing this article. The problem is that there is no good reason for believing that I am about to become a millionaire, just as there is no good reason to expect a reversal of the kind depicted in Cole's scenario. In the real world, logical possibility without the check of plausibility is a worthless guide to action.

\section{Logical fantasies and ordinary concepts}

The fears of premature organ removal, outlined in Cole's critique of the weak construal of irreversibility, can be met by appeal to further possibilities. One fantasy is as good as another. Thus organ seeds, manufactured by new unheard of techniques, could be sprinkled on dissected corpses so that lost structures could be restored, thus eliminating at a stroke, all the ethical problems of transplantation and a lot more besides. Yet it is hard to see how this is compatible with the ordinary concept of death. In Cole's world ordinary concepts of death would allow situations where grieving relatives could be told: 'She's only dead for the time being. Come back next week when we might have a reversal'. Despite Cole's appeal to logical possibility, the ordinary concept of death does not admit reversal.

When, in non-medical contexts, death is portrayed as a reversible state, with metaphors suggestive of temporal states, the language used does not convey a belief in possible physical restoration and consequently provides no support for Cole's critique of the medical concept of 
death. The meaning of the resurrections of Lazarus and Christ, and of the Day of Judgement when the dead shall rise, is a matter of dispute among theologians and philosophers of religion, and it is generally held that they are not accounts to be interpreted in a strong literal sense. These 'reversals' can only support Cole's thesis if they are stripped of their religious context and reduced to a simplistic propositional form. For example, Christ's resurrection cannot be communicated as an example of a reversal of brainstem death without losing much of its meaning in the Christian faith. A belief in the Day of Judgement is not equivalent to a belief that both cardiorespiratory and brain-related criteria for death are inaccurate. For ceremonial purposes a corpse may be spoken of as a being with moral attributes, but is nevertheless recognised as a corpse. The ancient Chinese left bowls of rice for the departed to take on the journey to the next world, but never really expected the corpse to recover and consume it. Many such elaborate funeral rites include references to the reversal and conquest of death but these indicate the grandeur of death and worth of the life that has passed away, rather than a superstitious prediction of unlimited physical duration. The promise of 'life eternal' is not a rebuke to the doctor who diagnosed death and withdrew therapy.

In their proper context many metaphors of reversibility are meaningful in relation to judgements concerning the quality of the life that has departed. In a ballad about a dead gangster, Joey, Bob Dylan refers to a friend at the funeral saying: 'He ain't dead. He's just asleep' (4). Given the context of these lines, it would be meaningless to construe them as a prediction of possible reversal; the meaning is to be understood in terms of a judgement concerning the alleged innocence of the life described in the ballad. Only a logician could interpret this as an example of reversal. Likewise, 'At Rest' on a tombstone does not mean that when the whistle blows he will be back at work. The ordinary use of the concept of 'reversible' is far richer than that portrayed by Cole. Expressions like 'At Peace', 'At Rest', 'Asleep' - all descriptions of reversible states attributed metaphorically to death - are bound up with the kind of things it is felt appropriate to say about the life which has passed. Metaphors of rest are appropriate for one whose labours in life have earned respect; as they are inappropriate for someone with a reputation for indolence. Religious and ordinary expressions of death reversal cannot be employed in a critique of medical irreversibility without serious damage to their original meaning. Cole's critique of medical definitions of death rest ultimately on an oversimplified account of religious and ordinary concepts.

Cole's appeal to divine intervention is clearly a case of a philosopher rushing in where theologians fear to tread. Once divine intervention is introduced then all bets are off as all physical laws can be transcended. This may be the case, but if the possible intervention of the deity is to serve as the basis of a critique of existing definitions and criteria for death then very good evidence for anticipating it should be adduced.

What is missing from Cole's appeal to the possibility of death reversal is the check of plausibility. Despite their freedom from contradiction some events are plainly impossible because they cannot be envisaged by extensions to our current thinking. Thus, to adapt an example from $\mathrm{H}$ M Collins (5), we cannot envisage a skin cream which would permit us to have a safe holiday on the surface of the sun. It would not matter if this impossibility were given either a strong or weak sense; that is, never or not just yet. Nothing that is logically possible about this could influence the future projects of travel agents or sun-worshippers.

The boundaries of logical possibility are as infinite as the boundaries of the imagination, governed only by selfcontradiction. But in the real world appeals to imagination are more restricted than many analytic philosophers believe (6). In ordinary life, medicine, science and religion, the scope of logical possibility is regulated by mechanisms of plausibility. The Dr X scenario is implausible as there are no satisfactory steps from current thinking and practice to the possibility stipulated.

If doctors are to be guided by ethical rules which take into consideration the possibility that death (not just dying from this or that disease) may be reversed, then a plausible account of the way existing knowledge can be extended in that direction is urgently required. It is not sufficient to appeal to the open-endedness of future medical knowledge or to extrapolate from modern therapeutic procedures which were not available in the past. There is, however, a role for a serious philosophical discussion of reversibility but this must involve an examination of the mechanisms by which theories and technical knowledge can be extended; not an open-ended appeal to logical possibility but through a detailed engagement with medical science and its actual problems.

David Lamb, BA, Ph D, is Senior Lecturer in Philosophy, University of Manchester. He is editor of Explorations in Knowledge, an international philosophy of science journal, and author of Death, Brain Death and Ethics, Down the Slippery Slope, Ethics and Organ Transplants, and several articles in medical ethics.

\section{References}

(1) BBC. Panorama, 1980 Oct 13.

(2) Pallis, C. Brainstem death. In: Braakman R, ed. Handbook of clinical neurology: head injury. Amsterdam: Elsevier, 1990; 13, 57: 441-496, especially 483.

(3) Cole, D J. The reversibility of death. Foumal of medical ethics 1991; 3: 25-29.

(4) Dylan B. 1975 Joey. Desire. CBS Inc.

(5) Collins H M. Artificial experts. Cambridge, Mass: MIT Press, 1990.

(6) See Lamb, D. Discovery, creativity and problem solving. Aldershot: Gower, 1991 for a criticism of the use of such examples and other appeals to logical possibility in the philosophy of science and the logic of diagnosis in medicine. 